\title{
Optimal scheduling of building integrated energy system based on demand response
}

\author{
Mengju Wei ${ }^{1}$, Yang Yang ${ }^{1}$, Mengjin $\mathrm{Hu}^{1}$, Yongli Wang ${ }^{2}$, Siyi Tao ${ }^{2}$, Minhan Zhou²* Yang Ma ${ }^{2}$, Fuhao Song ${ }^{2}$ \\ 1 Economic and Technological Research Institute of State Grid Hebei Electric Power Co., Ltd, Hebei 050000, China \\ 2 Departments of Economics and Management, North China Electric Power University, Beijing 102200, China
}

\begin{abstract}
With the development of renewable energy technology, integrating a variety of renewable energy integrated energy systems can effectively solve the problem of optimizing the scheduling of buildings with high energy consumption and fast growth rate. Based on the modeling and analysis of various energy equipment in the system, the integrated energy system of building buildings, based on the demand response compensation price, with the lowest construction operating cost as the goal function, establishes the optimization scheduling model of building-level integrated energy system based on demand response, and uses the particle group algorithm based on cloud model improvement to optimize the solution of the model. The study is introduced for simulation to compare the two different modes of participation in demand response, and the optimal performance of cloud model particle group algorithm and elementary particle group algorithm. The results show that the cloud model particle group algorithm model based on demand response can effectively save the operating cost of the building-level integrated energy system, and reduce the power grid side load peak and valley difference.
\end{abstract}

\section{Introduction}

The diversified development of building functions makes the connection between various energy-using equipment in the building more and more closely, and the requirements of comprehensive and systematic energy use are also put forward [1]. On the one hand, buildings have a variety of energy demand sourcing, but the energy structure is unreasonable, easy to increase the power grid side load peak and valley difference characteristics, on the other hand, buildings in the use of energy equipment flexible and diverse, energy efficiency is huge potential [2]. Technologies such as (pv system, PV), (wind turbine, WT), (combined cooling, heating and power system, CCHP), (battery, BT) and (thermal energy storage, TES) have been used in various types of buildings. These integrated energy systems in buildings, together with building energy consumption systems including air conditioning systems, hot water supply systems, lighting systems and office equipment, form a building-level integrated energy system. Based on the research of building-level integrated energy system, the power demand side response technology is introduced. Building integrated energy system to enhance the interaction with power grid side information by participating in demand response projects, to achieve the optimization of building electricity behavior [3]. Aiming at the function of building running cost, the improved particle group algorithm based on the cloud model is used to optimize the solution of the model. The simulation is introduced and compared with the basic particle group algorithm, the results show that the model constructed in this paper can effectively save the operating cost of the building-level integrated energy system and reduce the grid side load peak and valley difference. The structure of the building-level integrated energy system is shown in Figure 1.

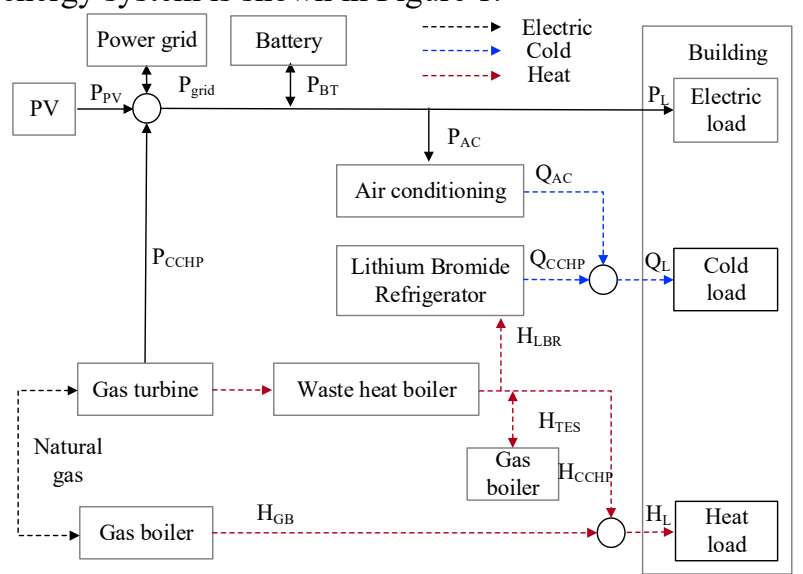

Fig. 1 Building-level integrated energy system structure

\footnotetext{
* Corresponding author: 15023620691@163.com
} 


\section{Building-level integrated energy system optimization scheduling model.}

\subsection{Objective function}

The purpose of optimizing the scheduling of buildinglevel integrated energy system is to make the total operating cost of the building lowest, including the cost of building gas purchase, the cost of electricity purchase and the compensation income of participating in the demand response, and the way of participation in demand response is to compensate the building operator for the user battery discharge and the central air conditioning transformation function, and the target function of the scheduling model is.

$$
\begin{gathered}
\operatorname{minJ}=\sum_{t=1}^{n}\left[C_{\text {elec }}^{t} P_{\text {grid }}^{t}+C_{\text {gas }}\left(V_{C C H P}^{t}+V_{G B}^{t}\right)-\right. \\
\left.C_{D R}\left(\sum_{i=1}^{N_{A C}} \Delta P_{i, A C}^{t}+P_{d B T}^{t}\right)\right] \Delta t
\end{gathered}
$$

In the formula: $\mathrm{J}$ is the total operating cost of the building; $C_{\text {elec }}^{t}$ is the unit electricity price for the t-period, yuan $/ \mathrm{kWh} ; P_{\text {grid }}^{t}$ is for time building and power grid exchange power, $\mathrm{kW} ; C_{g a s}$ is for the price of natural gas, $\mathrm{meta} / \mathrm{m}^{3} . V_{C C H P}^{t}$ and $V_{G B}^{t}$ are the intake capacity of CCHP and GB in the t-time period, respectively, $\mathrm{m}^{3} . C_{D R}$ is the compensate the price in response to demand, yuan $/ \mathrm{kWh} ; \Delta P_{i, A C}^{t}$ is the amount of power change that participates in the demand response for the first $i$ air conditioner in the t-time period, $\mathrm{kW} ; P_{d B T}^{t}$ is the discharge power of the battery for the t-time battery, $\mathrm{kW}$.

\subsection{Constraints}

(1) Battery operating constraints [4].

Considering the large difference between the power grid load peak and valley, the way for the battery to participate in demand response is to cut the peak and fill the valley, that is, to optimize the electricity consumption behavior according to the high and low price of electricity.

$$
0 \leq P_{d B T}^{t} \leq P_{d B T, \max }
$$

In the formula: $\mathrm{P}_{\mathrm{cBT} \text {,max }} 、 \mathrm{P}_{\mathrm{dBT} \text {,max }}$ are respectively represent the maximum charge and discharge power of the battery, $\mathrm{kW}, \mathrm{SOC}_{\mathrm{BT}, \min } 、 \mathrm{SOC}_{\mathrm{BT} \text {,max }}$ are respectively represent the minimum and maximum load states of the battery are $20 \%$ and $90 \%$.

(2) AC runs constraints [5]

Considering the user comfort issue, AC's approach to demand response is characterized by multi-energy complementarities, i.e. the lithium bromide chiller absorbs the residual heat of the gas turbine to bear some of the building cooling load.

$$
\begin{aligned}
& Q_{L B R}^{t}=Q_{C C H P}^{t}=\sum_{i=1}^{N_{A C}} \Delta P_{i, A C}^{t} \eta_{i, A C} \\
& 0 \leq \Delta P_{i, A C}^{t} \leq x_{\text {air }}^{t} P_{\text {air }}^{N}
\end{aligned}
$$

In the formula: $\eta_{i, \mathrm{AC}}$ is the performance factor for the I air conditioner.

(3) CCHP operating constraints [6]

$$
\begin{aligned}
& 0 \leq P_{G T}^{t} \leq P_{G T, \max } \\
& 0 \leq H_{G T}^{t} \leq H_{G T, \max }
\end{aligned}
$$

$$
\begin{aligned}
& 0 \leq H_{G B}^{t} \leq H_{G B, \text { max }} \\
& 0 \leq Q_{L B R}^{t} \leq Q_{L B R, \text { max }}
\end{aligned}
$$

In the formula: $\mathrm{P}_{\mathrm{GT}, \max } 、 \mathrm{H}_{\mathrm{GT}, \max } 、 \mathrm{H}_{\mathrm{GB}, \max }$ 、 $\mathrm{Q}_{\mathrm{LBR} \text {,max }}$ respectively represent the upper limit of the operating capacity of GT, GB and LBR, kW.(4) Heat storage tank operating constraints

$$
\begin{aligned}
& -H_{T E S, \max } \leq H_{T E S}^{t} \leq H_{T E S, \max } \\
& -T_{T E S, \min } \leq Z_{T E S}^{t} \leq Z_{T E S, \max } \\
& Z_{T E S}^{0}=Z_{T E S}^{48}
\end{aligned}
$$

In the formula: $H_{T E S, \max }$ is the upper limit of heat power storage and storage power for the storage tank, $\mathrm{kW} ; Z_{T E S, \max }, T_{T E S, \min }$ respectively represent the upper and lower limits of heat storage in the storage tank, $\mathrm{kWh}$; and the heat storage tank stores the same heat at the beginning and end of 48 periods of the day.

(5) Power balance constraints for building energy systems

$$
P_{P V}^{t}+P_{C C H P}^{t}+P_{\text {grid }}^{t}=P_{L}^{t}+P_{A C}^{t}+P_{B T}^{t}
$$

In the formula: $\mathrm{P}_{\text {grid }}^{t}$ is the power exchanged with the grid, $\mathrm{kW} ; \mathrm{P}_{\mathrm{L}}^{t}$ is the building basic power load, $\mathrm{kW}$.

(6) The cold energy balance constraint of the building energy system

$$
Q_{L}^{t}=Q_{A C}^{t}+Q_{C C H P}^{t}
$$

In the formula: $\mathrm{Q}_{\mathrm{L}}^{t}$ is the refrigeration load required for the construction, $\mathrm{kW} ; \mathrm{Q}_{\mathrm{AC}}^{t}$ is the refrigeration power for $\mathrm{AC}, \mathrm{kW}$.

(7) Thermal energy balance constraints for building energy systems [7]

$$
H_{L}^{t}=H_{G B}^{t}+H_{C C H P}^{t}
$$

In the formula: $\mathrm{H}_{\mathrm{L}}^{t}$ is the thermal load required for the building, $\mathrm{kW}$.

\section{The solution algorithm of the optimization scheduling model of the building-level integrated energy system}

\subsection{Basic particle group algorithm}

Particle swarm optimization is an optimization algorithm to simulate the foraging behavior of natural birds. A bird population is the equivalent of a "particle group" constructed in a multi-dimensional solution space, in which each particle constantly updates its speed and position by recording and sharing the optimal values found by itself and the group [8].

The formulas for particle update speed and displacement are respectively:

$$
\begin{aligned}
& v_{i, j}(t+1)=w v_{i, j}(t)+c_{1} r_{1}\left[p_{i, j}-x_{i, j}(t)\right]+ \\
& c_{2} r_{2}\left[P_{g, j}-x_{i, j}(t)\right] \quad(15) \\
& \quad x_{i, j}(t+1)=x_{i, j}(t)+v_{i, j}(t+1) j=1,2, \ldots, d \\
& (16)
\end{aligned}
$$

In the formula: $w$ is the inertia weight factor; $c_{1}$ and $c_{2}$ are positive learning factors; $r_{1}$ and $r_{2}$ are random numbers in $0-1 ; x_{i, j}(t)$ and $v_{i, j}(t)$ are respectively represent the position and velocity of the i particle at the t-time; $p_{i, j}$ is the individual optimal value for the ith particle iteration to date; $\mathrm{P}_{g, \mathrm{j}}$ is the global optimal value for all particles in the entire population. 


\section{Case study}

\subsection{Simulation of building energy systems}

In order to verify the validity of the model and algorithm, this paper takes the example of a super-high-rise office building in Qingdao, Shandong Province, for optimal simulation. The office has a total floor area of about $30,000 \mathrm{~m} 2$ and a total of 300 users. The building power supply bus absorbs electrical energy from photovoltaics, power grids and gas turbines, central air conditioning and other electrical loads (lighting, computers, etc.). The residual heat generated by the gas turbine is supplied with heat storage tanks, lithium bromide chillers and some building thermal loads by waste heat boilers, and the heat load of the other part is provided by the gas boiler spent on natural gas.

When the system generates enough electricity, it is purchased from the grid and sold to the grid when the surplus is made. The user's room temperature comfort range is taken to a range of 24,26 degrees $\mathrm{C}$, according to the formula (2)-(4) the user room temperature change curve can be obtained. The system consists of a gas turbine with a power ceiling of $600 \mathrm{~kW}$, a gas boiler with a power cap of $500 \mathrm{~kW}$, a residual heat boiler with a power cap of $1000 \mathrm{~kW}$, and a battery pack with a storage capacity of $2,500 \mathrm{kWh}$.

Natural gas using the domestic market price of 2.83 yuan / $\mathrm{m} 3$, the electricity price of the grid is time-sharing electricity price, peak period (10:00- 15:00, 18:00- 21:00) 0.98 yuan / $\mathrm{kWh}$, valley time (valley period) 0:00-7:00, 23:00) $0.35 \mathrm{yuan} / \mathrm{kWh}, 0.66 \mathrm{yuan} / \mathrm{kWh}$ for the rest of the period (the rest of a cycle), and the demand response compensation price adopted by the supplier is 0.5 yuan $/ \mathrm{kWh}$.

\subsection{Analysis of the results of the comparison of demand response and optimization algorithms}

To verify participation in demand response and the impact of cloud model particle cluster algorithms on simulation results, there are four scenarios: (1) Scenario 1: The system does not participate in the demand response and uses a basic particle cluster algorithm. (2) Scenario 2: The system does not participate in demand response but uses a cloud model particle cluster algorithm. (3) Scenario 3: The system participates in demand response but uses the elementary particle group algorithm. (4) Scenario 4: The system participates in demand response and uses a cloud model particle cluster algorithm.

The cost of building operation in 4 scenarios is shown in Table 1. The results show that although the cost of purchasing gas increased slightly after the user participated in the demand response, the cost of purchasing electricity decreased significantly and the total cost was reduced. Compared to Scenario 2, the total operating cost of the building in Scenario 4 mode can be $15.77 \%$ saving.
Tab. 1 Construction operating cost

\begin{tabular}{ccccc}
\hline $\begin{array}{c}\text { Schedule } \\
\text { the story }\end{array}$ & $\begin{array}{c}\text { Gas } \\
\text { cost }\end{array}$ & $\begin{array}{c}\text { Electricity } \\
\text { cost }\end{array}$ & $\begin{array}{c}\text { IDR } \\
\text { cost }\end{array}$ & $\begin{array}{c}\text { Total } \\
\text { cost }\end{array}$ \\
\hline 1 & 6588.09 & 11133.87 & 0 & 17721.96 \\
2 & 6751.82 & 10768.18 & 0 & 17520.01 \\
3 & 6765.99 & 9849.01 & 1249.37 & 15365.63 \\
4 & 6838.17 & 9513.5 & 1595.17 & 14756.5 \\
\hline
\end{tabular}

Compared with Scenario 2, Scenario 4 is more reasonable due to its involvement in demand response. The battery is charged at low electricity prices and discharged at peak times of high electricity prices or grid loads. In Scenario 4, the user increases the purchase power during the power supply trough period. That is to say, the electricity price is in the normal period and the valley period, and the power purchase power is reduced during the peak period of power supply of the power grid, which reduces the peak and valley difference of power load of the power grid. CCHP can be exported with a more flexible thermal ratio thanks to the involvement of lithium bromide chillers and heat storage tanks. CCHP increases thermal power during the period of electricity price valley, and increases the power output during the peak period of electricity price.

At the same time, the heat storage tank smooths the heat output of the gas turbine by means of flexible heat storage and release. In Scenario 2, the system does not participate in demand response, and all cold loads in the building are supplied by air conditioners regardless of the time. However, in Scenario 4, after the central air conditioner participates in the demand response, the shift to the peak period of electricity price is consumed by lithium bromide chiller scouring with relatively inexpensive natural gas supply and cooling, saving the operating cost of construction while also reducing the power load of the grid peak and valley difference.

\section{Conclusion}

Based on the demand response, the optimization and scheduling model of building-level integrated energy system is established, the simulation results show that participating in the demand response project can significantly reduce the operating cost of building buildings, while reducing the power load peak and valley difference of the power grid, improving the reliability of power supply of the power grid, and providing some guiding significance to the optimization of the buildinglevel integrated energy system.

\section{Acknowledgment}

This paper is supported by "Science and Technology Foundation of State Grid Corporatio-n of China (SG HEJY00NYJS2000055)".

\section{References}

1. YAN Qingguo, YANG Bin, XU Gaojie, et al. A strategy for intelligent power utilization in building 
based on adaptive PSO [J]. Power Demand Side Management, 2016, 18 (4) : 1-5, 30.

2. XI Nan. New requirements of distributed PV systems connected to the grid $[\mathrm{J}]$. Power Demand Side Management,2014, 16 (3) : 33-35.

3. PENG Liang. Analysis of factors to affect stability of grid connected wind turbines system $[\mathrm{J}]$. Electronic Design Engineering, 2017, 25 (15) : 85-89.

4. WU Guoliang, ZHANG Mingjiang, YU Haiyang, et al. Research on operation modes of electric vehicle charging station with wind / PV / battery energy storage[J]. Distribution\& Utilization, 2017, 34 (4) : 24-28.

5. XIONG Yan, WU Jiekang, WANG Qiang, et al. An optimization coordination model and solution for combined cooling, heating and electric power systems with complimentary generation of wind, PV, gas and energy storage $[\mathrm{J}]$. Proceedings of the CSEE, 2015 (14) : 3616-3625.

6. XUE Xinbai. Mode assessment of CCHP system with photovoltaic-battery system $[\mathrm{J}]$. Power Technology, 2017, 41 (7) : 1035-1038.

7. WANG Hui, ZHAO Jun, AN Qingsong, et al. Study on optimization and policy incentives of distributed energy system under different building loads $[\mathrm{J}]$. Proceedings of the CSEE, 2015 (14) : 3734-3740.

8. LIU Chuhui, ZHENG Yi, CAI Xu, et al. Intelligent economic scheduling for multi - type cooling system in high buildings $[\mathrm{J}]$. Modern Building Electric, 2014 (8) : 5-10. 